\title{
Degradation of 4-chlorophenol using advanced oxidative processes and artificial neural network modelling
}

\author{
Lira, D. A. $\mathrm{H}^{\mathrm{a}^{*}}$, Zaidan, L. E. M. C ${ }^{\mathrm{a}}$, Silva, A. M. R. B ${ }^{\mathrm{a}}$, Brandão, Y. B ${ }^{\mathrm{b}}$, \\ Napoleão, D. C ${ }^{\text {a }}$, Benachour, $M^{\mathrm{a}}$, Silva, V. L ${ }^{\mathrm{a}}$. \\ ${ }^{a}$ Department of Chemical Engineering, Universidade Federal de Pernambuco, Av. Prof. Arthur de Sá, S/N, \\ CidadeUniversitária, Recife 50740-521, Brazil \\ ${ }^{b}$ Academic Unit of Cabo de Santo Agostinho, BR-101 Sul, $n^{\circ}$ 5225, Ponte dos Carvalhos, Cabo de Santo \\ Agostinho - PE, Brazil
}

\begin{abstract}
The environmental issues which the world currently faces, due to the great water, air and soil pollution, caused mainly by continuos population growth and consequently by the surge in consumption is increasingly becoming a matter of concern. Industrial activities can largely generate a wide range of hazardous effluents which, in many cases, are not subject to adequate treatment and are discharged to the environment. Such contaminants have therefore become an issue of growing concern, resulting in various studies and the development of processes aiming at quantifying, degrading or even mineralising these pollutants. In this regard, the Advanced Oxidation Processes (AOPs) represent a promising solution to this issue. These processes make use of catalysed oxidation reactions for the degradation of several organic or inorganic compounds. This work evaluated the identification, quantification and degradation of 4-Chlorophenol by AOPs, being determined and quantified by a validated high-performance liquid chromatography method. The degradation process was modelled using Artificial Neural Networks (ANNs), in the types of Multilayer Perception (MLP) and Radial BasisFunction (RBF), in order to draw conclusions regarding the similarity between simulations and the processes. Among all experiments carried out, on both the UV-C and Sunlight-driven systems, it was observed that the better results of degradation of the compound took place in the centre point of the experimental design (5mg $\mathrm{L}^{-1}$ of $\mathrm{Fe}^{2+}, 0.75 \mathrm{~mL}$ of $\mathrm{H}_{2} \mathrm{O}_{2}$ and $90 \mathrm{mins}$ ). The ANNs modelling was considered precise on both types of networks studied and on both degradation systems evaluated. The linear regression coefficients found for the networks investigated were of 0.99, and the residual plots showedno pattern in the residuals, being dispersed around the horizontal axis. A sensitivity analysis was also carried out, having identified that the levels of $\mathrm{Fe}^{2+}$ and time are the variables which affect the process the most, corroborating with the experimental results.
\end{abstract}

Keywords: 4-Chlorophenol. Degradation.Advanced Oxidation Processes.Artificial Neural Networks.

\section{Introduction}

The growing demand for feedstock for various uses, among them industrial uses, have together led to an increase in the recovery, recycling and reuse of such materials - mainly water - and the recycling or degradation of the subproducts generated. The discharge of industrial effluents on waterways, on the soil and atmosphere represent a great threat to all living creatures reliant on these affected environments (He et al., 2015; Garba and Rahim, 2016; Sun et al., 2016). The aromatic organic pollutants represent a wide range of substances hazardous to the environment. These contaminants consist of a varied group of compounds largely found in industrial effluents, in the form of feedstock in some processes or as subproducts in the others (Cunha and Aguiar, 2014). Among the organic compounds, phenol and its derivatives are themain pollutants and are characterised by their high toxicity, stability and bioaccumulation potential on animals and plants (Peng et al., 2016). Considering the nocive aspects described, there is an ongoing need of developing degradation methods and the consequent removal of these phenolic compounds from effluents. Regarding chlorophenols, there are several processes used in its treatment, such as enzymatic electrocatalysis, adsorptive processes or biological treatment (Chen et al., 2015; Ding et al., 2015; Nourmoradi et al., 2015; Penghui et al.,2015). The Advanced Oxidation Processes (AOPs), based on the formation of highly-reactive species, mainly hydroxyl radicals $(\cdot \mathrm{OH})$, is another example of methods that have been successfully used in the treatment of these compounds (Vallejo et al., 2015; Zhong et al., 2012). Although considered efficient methods, the AOPs feature a complex reaction mechanism, mainly due to the lack of selectivitiy of the hydroxyl radical, with the reactions occuring in different ways, making the use of kinetic phenomenological models very problematic. Aiming at solving such problem, the Artificial Neural Networks (ANNs) have been used as a mathematic and optimisation modelling tool of such systems (Brandão et al., 2013). Taking into account the elements mentioned above, this work evaluates the degradation of 4chlorophenol using AOPs and ANNs modelling. 


\section{Materials}

\section{Materials and methods}

4-Chlorophenol $\left(\mathrm{C}_{6} \mathrm{H}_{5} \mathrm{ClO}\right)$ Chem Service (purity $\left.\geq 99.5 \%\right)$,Phosphoric acid $\left(\mathrm{H}_{3} \mathrm{PO}_{4}, 85-88 \%\right.$, Merck) and methanol $\left(\mathrm{CH}_{3} \mathrm{OH}\right.$, Merck). Ferrous sulfate heptahydrate $\left(\mathrm{FeSO}_{4} \cdot 7 \mathrm{H}_{2} \mathrm{O}\right)$ and hydrogen peroxide $\left(\mathrm{H}_{2} \mathrm{O}_{2}\right)$, dynamics of $30 \%$.

\section{Analytical Methods}

The quantification and identification of 4-chlorophenol was made using a high-performance liquid chromatographer (HPLC), model Shimadzu SS-550, equipped with an ULTRA C18 column of reversed-phase $(5 \mu \mathrm{m} ; 4.6 \times 250 \mathrm{~mm})$ and an UV spectrophometric detector (SPD-20A). The absorption of 4-chlorophenol had a retention time of 10 minutes, and was measured in length at $280 \mathrm{~nm}$. A chromatographic system in isocratic mode was used with a mobile phase constituted of a water solution acidified with phosphoric acid at $10 \%(\mathrm{v} / \mathrm{v})$ and methanol at a ratio of 60:40. The temperature of the oven was kept at $40 \pm 1^{\circ} \mathrm{C}$, with a flow of $1 \mathrm{~mL}^{-\mathrm{min}^{-1}}$ and pressure of $105 \mathrm{kgfcm}^{-2}$.

\section{Validation methology}

The parameters analysed for the validation of the analytical methods were: linearity, detection limits (LOD), limit of quantification (LOQ), precision and accuracy.

\section{Linearity}

Linearity was obtained using the Method of Least Squares, used to estimate the coefficients of the analytical curve, and can be described by Eq. 1 .

$\mathrm{Y}=\mathrm{ax}+\mathrm{b}$

Where:

$\mathrm{Y}=$ dependent variable, measured response;

$\mathrm{X}=$ independent variable, concentration of analyte;

$a=$ angular coefficient, expresses the slope of the line; and $b=$ linear coefficient, indicates the $y$-intercept.

\section{Detection Limit (LOD) and Quantification Limit (LOQ)}

The LOD and LOQ were estimated considering the noise level to analytical signal ratio, based on the curve and according to equations (2) and (3), respectively:

$$
\begin{aligned}
& \mathrm{LOD}=3.3 * \mathrm{~s} / \mathrm{s} \\
& \mathrm{LOQ}=10 * \mathrm{~s} / \mathrm{s}
\end{aligned}
$$

Where:

$\mathrm{s}=$ standard deviation of the blank,

$\mathrm{S}=$ slope of the calibration curve.

\section{Precision}

The precision was evaluated in terms of repeatability. The results of the precision were expressed as a coefficient of variation (VC), calculated according to Eq. (4):

$R S D(\%)$ or $C V(\%)=\frac{s}{\bar{x}} \times 100$

with:

$\mathrm{s}=$ standard deviation of the blank,

$\mathrm{x}=$ blank mean

\section{Accuracy}

Accuracy was measured using the Standard Addition method, adding known concentrations to the sample solution. In practice, the recovery study is carried out using a known addition to the sample concentration to be analysed. Three concentration levels should be selected for the recovery testing, and should cover the range of application of the method (Ribani et al., 2004). For more complex samples, an acceptable recovery varies from $50 \%$ to $120 \%$ (Lanças, 2009; Perlatti et al., 2012). The recovery (R) is therefore calculated according to Eq (5). 
$R(\%)=\left(\frac{C_{1}-C_{2}}{C_{3}}\right) \times 100$

with:

$\mathrm{C}_{1}=$ Concentration of the analyte with standard addition;

$\mathrm{C}_{2}=$ Concentration of the analyte without standard addition;

$\mathrm{C}_{3}=$ Concentration of the standard addition.

\section{Grubb's Test}

Grubb's test is used to detect a value that is outlier in a univariate data set. Equations 6 and 7 were used for this calculation:

$G_{<}=\frac{x-x_{i<}}{s}$

$G_{>}=\frac{\bar{x}-x_{i>}}{s}$

With:

$\mathrm{G}>=$ Tests whether the maximum value is an outlier;

$\mathrm{G}<=$ Tests whether the minimum value is an outlier;

$\mathrm{X}=$ Sample mean;

$\mathrm{x}>=$ maximum value;

$\mathrm{x}<=$ minimum value.

\section{Configuration of the annular reactor for the degradation of 4-chlorophenol (UV-C and Sunlight-driven} Systems)

The trials were carried out in $50 \mathrm{~mL}$ reactors. The UV-C system consisted of three $30 \mathrm{~W}$ Ecolume germicidal light bulbs, arranged in parallel on top of the set (Figure 1(b)). The sunlight-driven system consisted of a 300W Osram Ultra-Vitalux light bulb placed on top of the set (Figure 1(a)). Six experiments were carried out, being 3 for each system, under the same experimental conditions.

The procedure was as following: the Light intensity was initially measured using MRU-201 and UV-C MRU203 Solar Radiometers; then, eleven reactors were each filled with $50 \mathrm{~mL}$ of the $100 \mathrm{mg} \cdot \mathrm{L}^{-1}$ 4-chlorophenol solution; The established quantities of hydrogen peroxide, according to the factorial design, were added to each reactor; Time counting began; At the time periods established in the factorial design, the samples were removed, filtered and stocked for subsequent analysis in the Chromatograph.

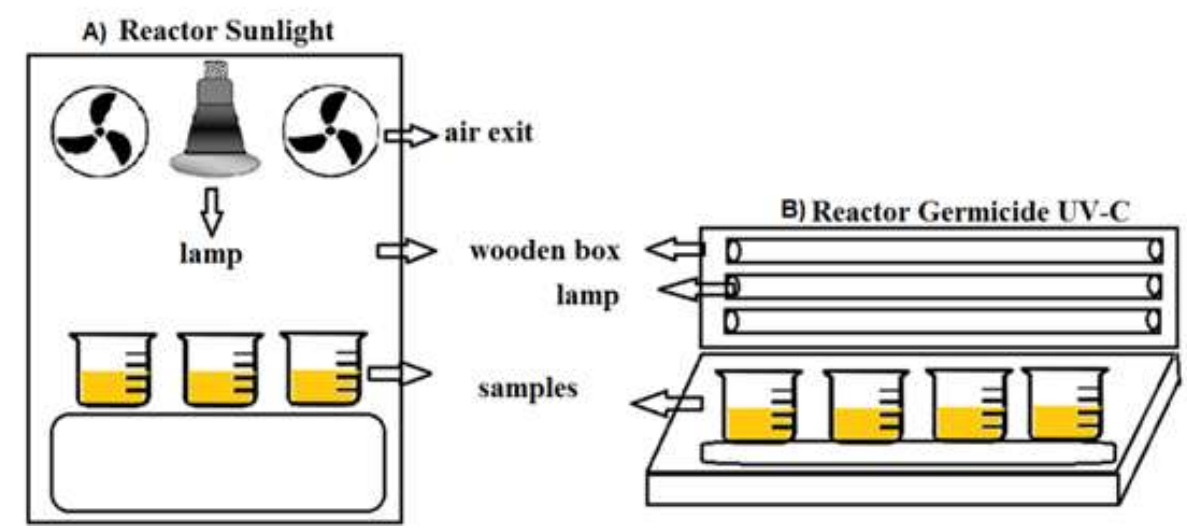

Figure 1: Systems Layout. a) Sunlight-driven; b) UV-C.

\section{Experimental Design}

All experiments used a $2^{3}$ full factorial design, with centre point runsin triplicate, in a total of 11 experiments. The following independent factors were used: $\mathrm{Fe}^{2+}$ concentration, $\mathrm{H}_{2} \mathrm{O}_{2}$ concentration and time (Table 1). The 
experiments were run and evaluated in order to identify the best experimental conditions for the degradation of 4-Chlorophenol.

Table 1: Variables studied in the Factorial Experimental Design.

\section{Artificial Neural Network Modelling (ANNs)}

A computational tool (ANNs) from the Statistica 8.0 software was used for the data modelling obtained from the experimental design. The inputs chosen were the experimental variables: $\mathrm{Fe}^{2+}$ concentration, volume of $\mathrm{H}_{2} \mathrm{O}_{2}$ and time; with the output selected being 4-Chlorophenol degradation. This was a random sampling method and divided in $70 \%$ for training, $15 \%$ for testing and $15 \%$ for validation. The activating functions chosen for the neurons chosen were the identity, logistics, hyperbolic, exponencial and sine functions. A minimum of 3 and maximum of 10 neurons were chosen for each hidden layer of the networks. 2000 iterations were executed for each training. In each system were then selected the best results from the MLP (Figures 2(a) and 2(b)) and RBF networks (Figures 2(c) and 2(d)) for the treatment using solar and UV-C radiation, respectively. The selection was based on the best values of the correlation coefficient $\left(R^{2}\right)$ from the training and the test; with the results being then analysed for the validation of the ANN modelling.

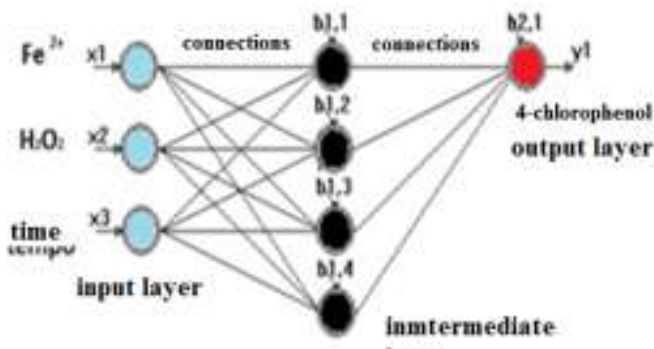

(a) MLP

layer

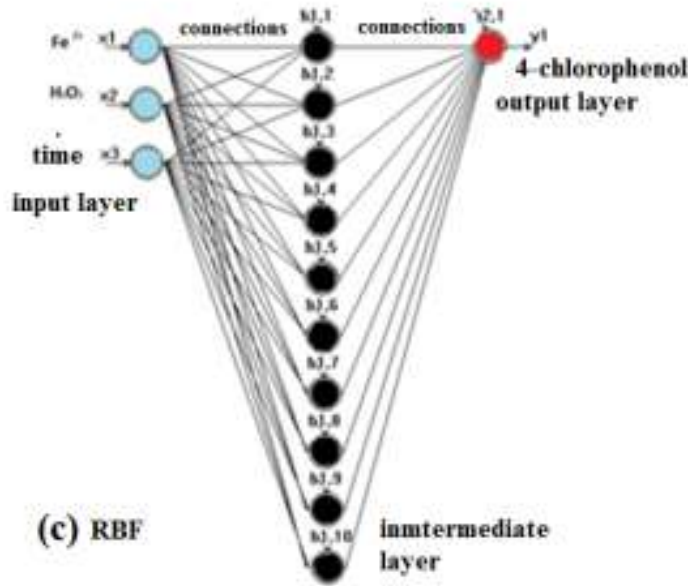

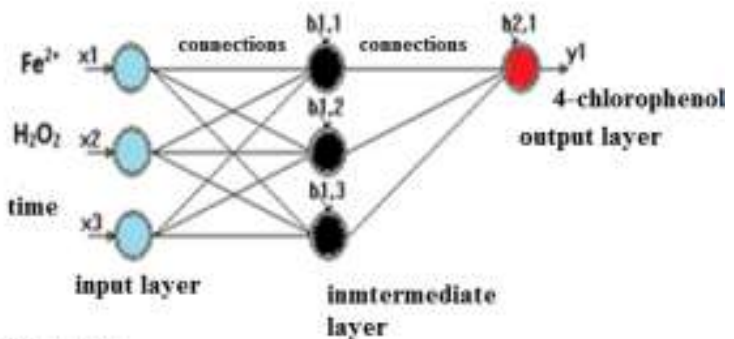

(b) MLP

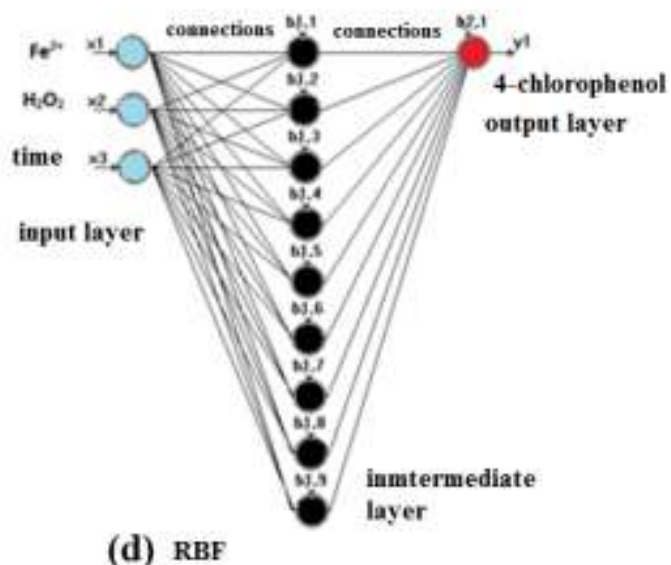

(d) RBF

Figure 2: Diagrams of the MLP ANNs architectures.a) MLP 3-4-1 BFGS 42 UV-C System; b) MLP 3-3-1 BFGS 33 Sunlight-driven System; Diagrams of the RBF ANNS. c) RBF 3-10-1 RBFT UV-C System; d) RBF 3-9 1 RBFT Sunlight-driven System.

Validation of the Methodology

\section{III.Results and Discussion}

The validation of the detection method of 4-chlorophenol started with the preparation of the analytical curve, which was obtained from the preparation and analysis of the eight compound solutions ( 10 to $\left.80 \mathrm{mg} \cdot \mathrm{L}^{-1}\right)$. Table 2 presents the results of the areas obtained, as well as the calculated mean values.

\section{Table 2: Areas obtained from all trials.}

\section{Linearity}

Based on the concentrations and the mean area values described in Table 2, the analytical curve was plotted (Figure 3). 


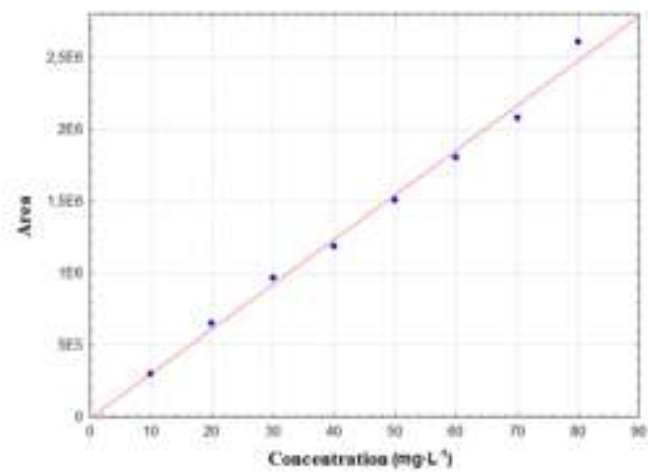

Figure 3: Analytical curve of 4-chlorophenol.

From the graph were obtained the straight line equation and the linear regression coefficient $\left(\mathrm{R}^{2}\right)$ :

$\mathrm{y}=31057 \mathrm{x}-11933$

With $\mathrm{R}^{2}=0.9916$

The Brazilian National Institute of Metrology, Quality and Technology (INMETRO) established that the correlation coefficient $\left(\mathrm{R}^{2}\right)$ should be higher than 0.90 and that the number of samples should be equal to seven or higher. Yet, the Brazilian National Health Surveillance Agency (ANVISA) states that $\mathrm{R}^{2}$ should be greater than 0.99 , and that the number of samples should equal to or greater than 5 . The values found therefore comply with the norms of the national regulatory bodies.

Precision

From the mean values obtained, were calculated the standard deviation, through an analysis using Grubb's Test and the Coefficient of Variation (CV). The results are listed in Table 3.

Tabela 3: Precision Analysis.

Grubb's Test establishes that, for every 7 measurements, the values found should be lower than 2.020 so that the results are approved with $95 \%$ of confidence level. Therefore, all results found are accordingly (LANAGRO, 2014).

The results of the CVs obtained in Table 3 are according to the requirement, which are values lower than $20 \%$ (RIBANI et al., 2004).

\section{Accuracy}

Table 4 presents the results of the percentages of recovery of 4-chlorophenol. The values were obtained from experiments run in triplicate of the concentrations $(10+20),(10+40)$ and $(10+60) \mathrm{mg} \cdot \mathrm{L}^{-1}$ and the subsequent calculation of the mean results.

Table 4: Accuracy Analysis.

For the method to be considered accurate, the recovery rate should be between 50 and $120 \%$ (Perlatti et al., 2012). As all results found are according to such requirement, it is therefore concluded that the analytical method is indeed reliable.

Quantification Limit (LOQ) and Detection Limit (LOD)

The LOQ and LOD of 4-chlorophenol were obtained from Equations 4 and 5, respectively. The values found were of $\mathrm{LOQ}=5.175 \mathrm{mg} \cdot \mathrm{L}^{-1}$ and $\mathrm{LOD}=1,708 \mathrm{mg} \cdot \mathrm{L}^{-1}$.

Degradation of 4-chlorophenol using the photo-Fenton process $\left(\mathrm{Fe}^{2+} / \mathrm{H}_{2} \mathrm{O}_{2} / \mathrm{UV}\right)$

The $100 \mathrm{mg} . \mathrm{L}^{-1}$ 4-chlorophenol solution was submitted to a degradation process in the UV-C and Sunlightdriven reactors, with radiation emissions of $1.526 \mathrm{~mW} . \mathrm{cm}^{2}$ and $1.148 \mathrm{~mW} . \mathrm{cm}^{2}$, respectively. Three degradations were carried out in each system, with each containing eleven trials run threefold at the centre point, according to

DOI: $10.9790 / 2402-1103027486 \quad$ www.iosrjournals.org $\quad 78 \mid$ Page


the factorial design proposed in the method. Following the degradation, the solutions were submitted to a HLPC analysis, being found that the best results on both reactors were at the centre points, under the following conditions: concentration of $\mathrm{Fe}^{2+}$ ions $=5 \mathrm{mg} \cdot \mathrm{L}^{-1}, \mathrm{H}_{2} \mathrm{O}_{2}=0.75 \mathrm{mg} \cdot \mathrm{L}^{-1}$ and time $=90$ minutes. Under these circumstances, for the UV-C system, the compound was no longer detected and, for the Sunlight-driven system, the compound was almost completely degraded on the first and third trials, with the compound being completely degraded on the second trial.

Based on such results, an analysis of variance (ANOVA) was carried out in order to verify the adjustment of the experimental model on the reaction systems evaluated (Tables 5 and 6).

\section{Table 5: Analysis of variance of the 4-Chlorophenol degradation model for the UV-C System.}

Table 6: Analysis of variance of the 4-Chlorophenol degradation model for the Sunlight-driven System.

\section{Proportion of variance}

The proportion of variance explained was equal to $77.09 \%$ for the UV-C system, and of $88.37 \%$ for the Sunlight-driven system, and is given by the ratio of the residual sum of squares to the total sum of squares (total variation). The maximum value is given by the difference of the total sum of squares and the mean square of the pure error divided by the total sum of squares, being equal to $99.99 \%$ for the UV-C system and to $100 \%$ for the Sunlight-driven system. Comparing the explained variable in the model $(77.09 \%$ and $83.37 \%)$ with the maximum value explained $(99.99 \%$ and $100 \%)$, it can be observed that such values are similar, but for more satisfactory results a better adjustment is required, such as when using a Factorial Experiment with a Central Composite Rotatable Design (CCRD). Figure 4 shows Pareto Charts of 4-chlorophenol degradation in the UV-C and Sunlight-driven Systems, respectively.
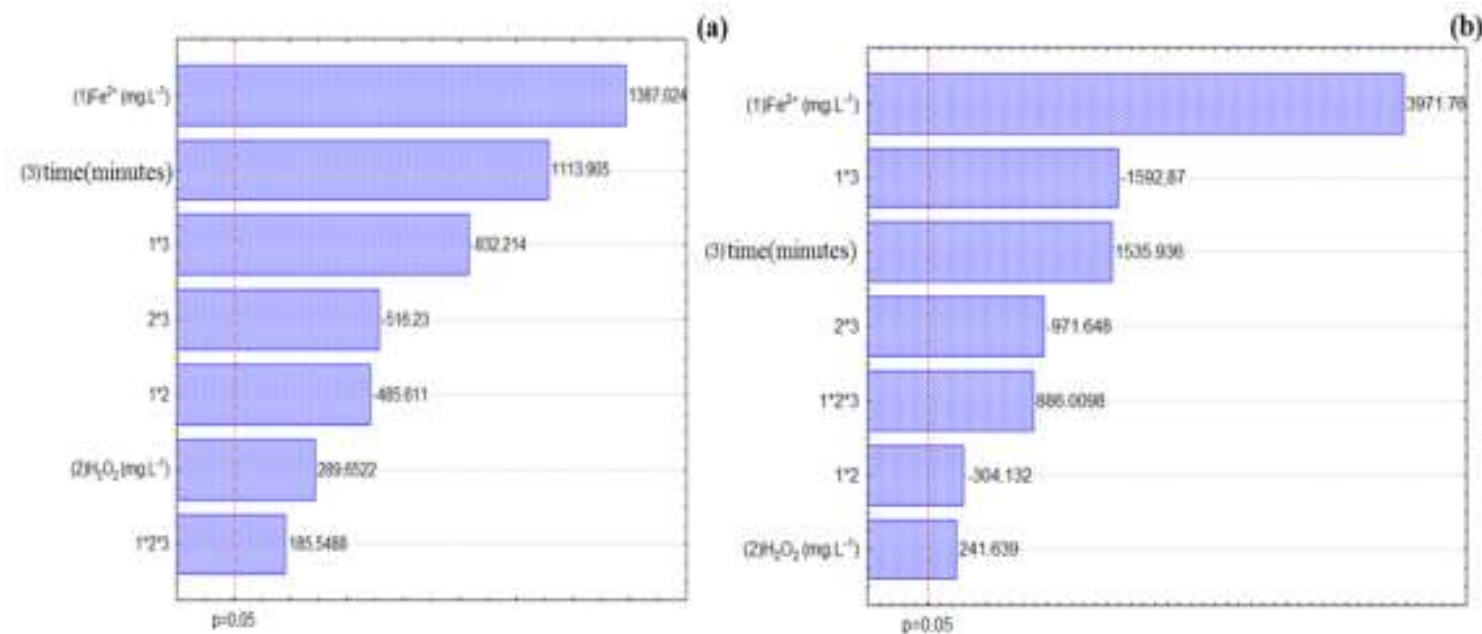

Figura 4:Pareto Charts of 4-Chlorophenol Degratation with UV-C and Sunlight-stimulated lamps.

The study of these charts, done for a 95\% confidence level, can indicate that for both trials all variables and interactions are considered significant, but that the concentration of $\mathrm{Fe}^{2+}$ ions, followed by the time variable, are the most relevant factors and their interaction represents the most significant combination.

For a better view of the effects of the interaction between both factors, Response surfaces were plotted for both systems (Figures 5(a), (b) and (c)). In Figure 5(a) it is observed that the degradation increases for higher concentrations of ions of iron (II) for a longer reaction time. Therefore, for $10 \mathrm{mg} \cdot \mathrm{L}^{-1}$ of $\mathrm{Fe}^{2+}$ and after 120 minutes of reaction, occurred the highest degradation level of the compound. In Figure 5(b), the highest degradation is related to the increase in $\mathrm{Fe}^{2+}$ ions and the reduction in volume of $\mathrm{H}_{2} \mathrm{O}_{2}$, with the highest degradation of the aromatic compoundbeing found for $10 \mathrm{mg} \cdot \mathrm{L}^{-1}$ of $\mathrm{Fe}^{2+}$ and $0.5 \mathrm{~mL}$ of peroxide. Figure 5 (c) shows that the highest 4-chloropohenol degradation was observed for lower volumes of peroxide and aftera longer time period; thus, for $0.5 \mathrm{~mL}$ of peroxide and after 120 minutes took place an almost complete degradation of the organic compound. 


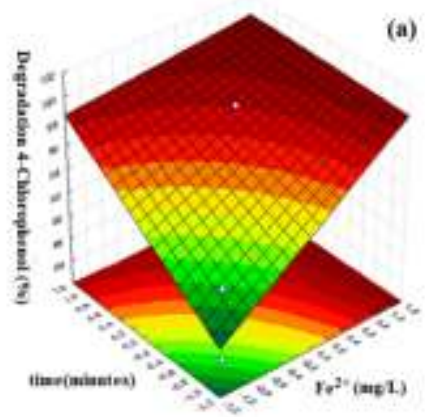

(a)

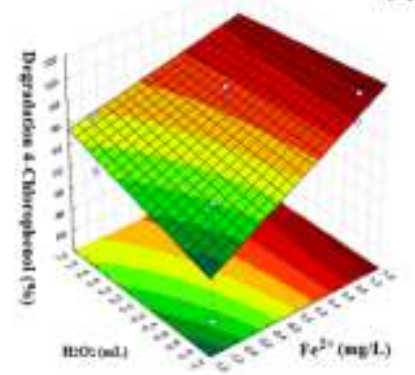

(b)

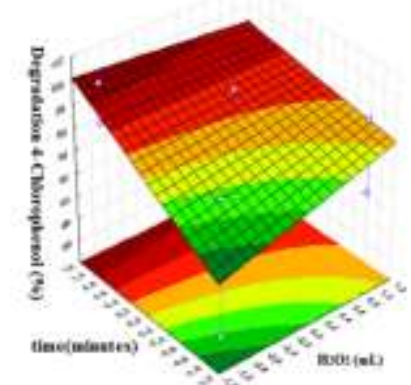

Figura 5: Surface Graphs: a) Interaction between iron ions and time; b) Interactionbetween $\mathrm{H}_{2} \mathrm{O}_{2}$ and iron ions ; c) Interaction between $\mathrm{H}_{2} \mathrm{O}_{2}$ and time inthe UV-C System.

By analysing Figure 6(a), it is noted that the highest degradation occurred with the increase in concentration of iron ions and after longer reaction times, with 4-cholorophenol degradation being almost $100 \%$ for $10 \mathrm{mg} \cdot \mathrm{L}^{-1}$ of $\mathrm{Fe}^{2+}$ and after 120 minutes. Figure 6(b) shows that the highest degradation level is verified for a higher concentration of iron(II) ions and for a lower volume of peroxide, for $10 \mathrm{mg} \cdot \mathrm{L}^{-1}$ of $\mathrm{Fe}^{2+}$ and $0.5 \mathrm{~mL}$ of $\mathrm{H}_{2} \mathrm{O}_{2}$. Finally, in Figure 6 (c), higher degradation levels can be observed for a greater reaction (120 minutes), combined with a lower volume of hydrogen peroxide $(0.5 \mathrm{~mL})$.
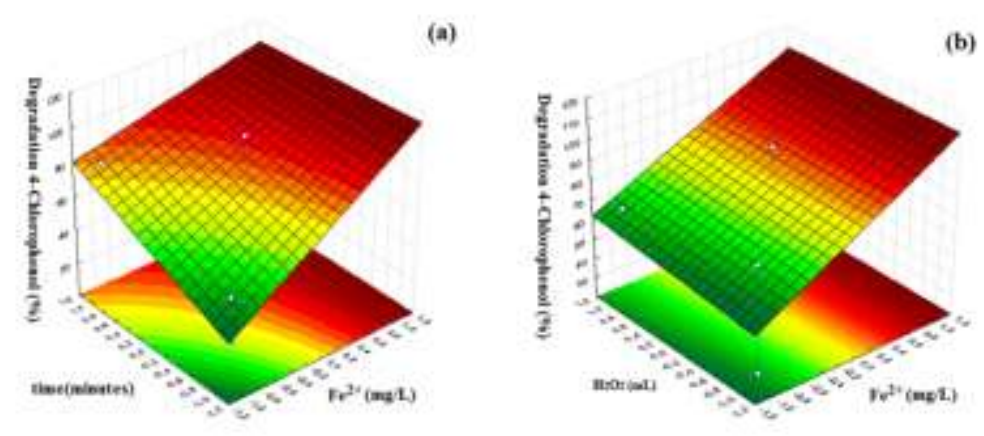

Figura 6: Surface Graphs: a) Interaction between iron(II) ions and time; b) Interaction between $\mathrm{H}_{2} \mathrm{O}_{2}$ and iron(II) ions; c) Interaction between $\mathrm{H}_{2} \mathrm{O}_{2}$ and time in the Sunlight-driven System.

It is worth noting that, in all experiments and in both reaction systems, the highest degradation occured for a lower volume of hydrogen peroxide $(0.5 \mathrm{~mL})$. This was possibly due to the excess of $\mathrm{H}_{2} \mathrm{O}_{2}$ in the reaction medium, considering that the stoichiometric quantity of peroxide needed to completely mineralise 4chlorophenol is of $0.056 \mathrm{~mL}$. The great excess of peroxide can hamper the degradation reactions of the organic compound due to the possible recombinations of the hydroxyl radical, therefore impairing the efficiency of the process.

\section{Artificial Neural Network Analysis}

Selecting Results

Of all simulations carried out, were selected the best results from the MultilayerPerceptron (MLP) and Radial Basic Function (RBF) models. Tables 7 and 8 show these results for the UV-C and Sunlight-driven Systems, respectively; with the average training, testing and validation correlation coefficient being of 0.99 .

\section{Tabela7: Characteristics of resulting ANNs for the UV-C System.}

\section{Tabela 8: Characteristics of resulting $\mathrm{ANN}_{\mathrm{S}}$ for the Sunlight-driven System.}

It is observed that for the UV-C system (Table 7), the MLP model resulted in four neurons in the hidden layer. The activation function used in the hidden layer was the Hyperbolic (Tanh) and Identity in the output layer regarding the RBF model, it resulted in ten neurons in the hidden layer; the activation function used in the hidden layer was the Gaussian Function, and the Identity function in the output layer. 
For the Sunlight-driven system (Table 8), the MLP model resulted in nine neurons in the hidden layer. The activation function used in the hidden layer was the Hyperbolic function, and the Sine Function in the output layer. For the RBF model, nine neurons were used in the hidden layer; with the activation function used in the hidden layer being the Gaussian function, and the Identity function in the output layer.

Tables 9-12 present the weights of the input and output variables, as well as of the hidden layer obtained for the MLP and RBF ANNS in the UV-C and Sunlight-driven systems.

Tabela 9: Weights of the input, hidden and output layers for the MLP ANN in the UV-C System.

Tabela 10: Weights of the input, hidden and output layers for the MLP ANN in the Sunlight-driven System.

Tabela 11: Weights of the input, hidden and output layers for the RBF ANN in the UV-C System.

Tabela 12:Weights of the input, hidden and output layers for the RBF ANN in the Sunlight-driven System

\section{Comparison between the Experimental and Simulated Models}

$U V$-C System

With the residual analysis, a good correlation between experimental and predicted values in the simulations is noticeable; with Figures 7(a) and 7(b) showingthe comparison between such values. Furthermore, Figures 7(c) and 7(d) present the straight line equations that best adjust the data, with the linear regression coefficient $R^{2}=$ 0.9331 for the MLP model and $\mathrm{R}^{2}=0.9929$ for the RBF model. In Khatamian et al (2012) was applied an artificial neural network to describe the non-linear behavior of 4-nitrophenol and was obtained as linear regression coefficient $\mathrm{R}^{2}=0.982$ using a network of three layers with a sigmoidal transfer function (trainscg) with back propagation algorithm was designed. In Rasolifard et al. (2016) reached $R^{2}=0.991$ for the MLP model for degradation of organic compounds such as dyes.

Figures 8(a) and 8(b) exhibit the residual plots; result of the difference between the experimental and calculated data. It is evident that the data are distributed randomly and close to zero, demonstrating that experimental values are in good fit with the predicted values. Therefore, it is possible to state that the ANNs predict a similar behaviour to the one displayed in the UV-C System.
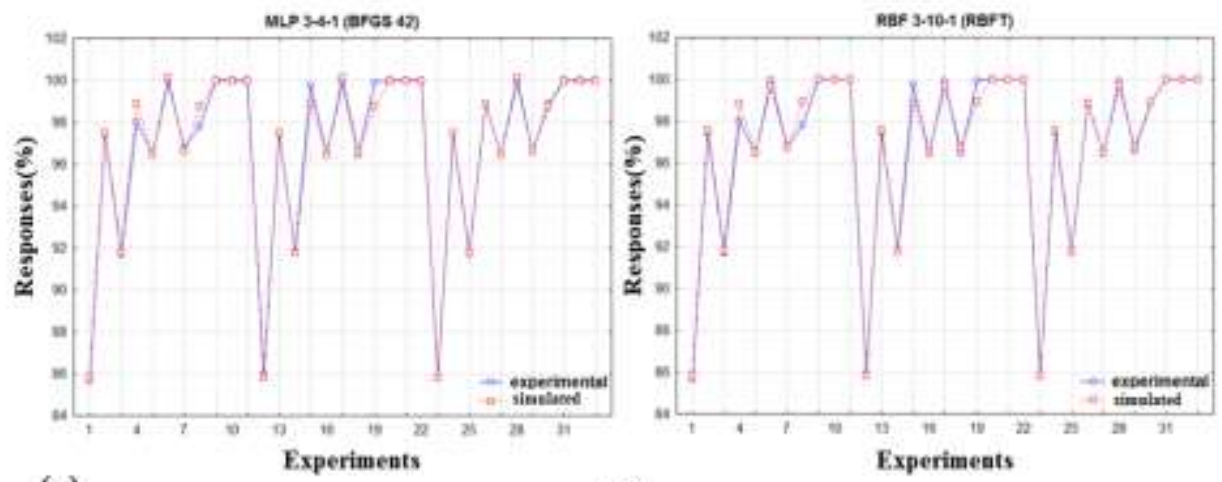

(a)

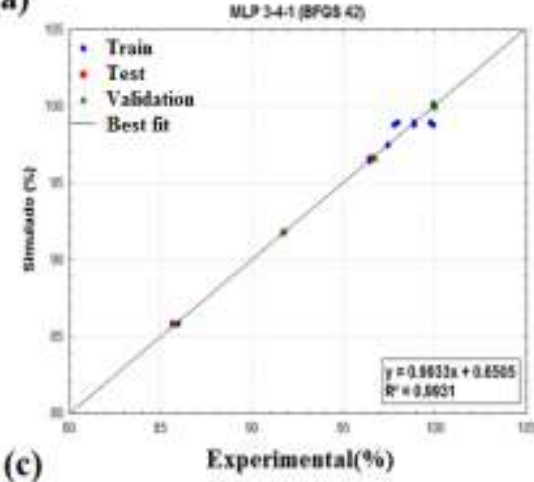

(b)

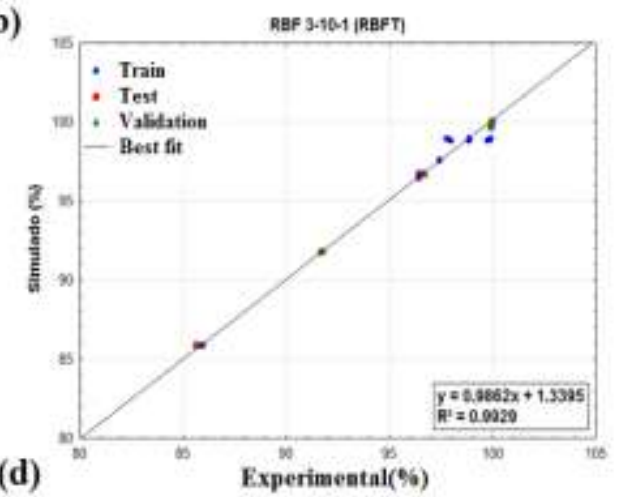

Figure 7: Comparison between the experimental and simulated results. A) MLP; B) RBF. Linear regression between experimental and simulated results. c) MLP; d) RBF. 

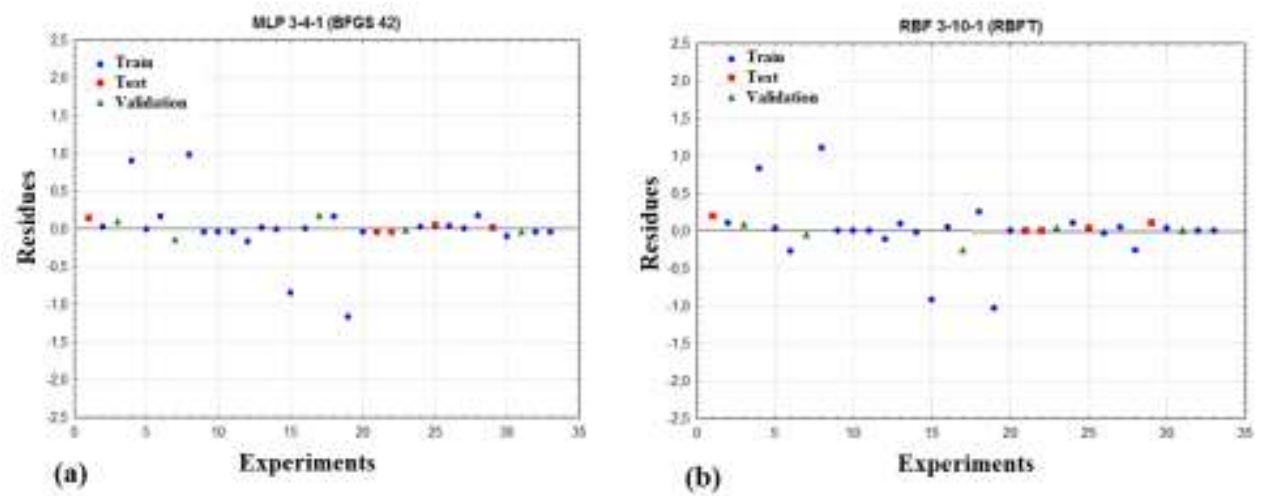

Figure 8: Residual plot of 4-chlorophenol degradation, regarding the difference between experimental and simulated values using ANN models. a) MLP; b) RBF.

Sunlight-driven system

Similarly to the UV-C system, a good correlation between values is noticeable. Figures 9(a) and 9(b) illustrate the comparison between experimental and simulated values. Figures 9(c) and 9(d) exhibit the linear regression between experimental and simulated values and demonstrate a good correlation between values, with $\mathrm{R}^{2}=0.9997$ for both models. The residual plots (Figures 10(a) and 10(b)) also show the random distribution of values, and their proximity to zero, demonstrating that the experimental values are in good fit with the predicted values. Therefore, just as in the UV-C system, the ANNs satisfactorily represented the behaviour of the Sunlight-driven system.
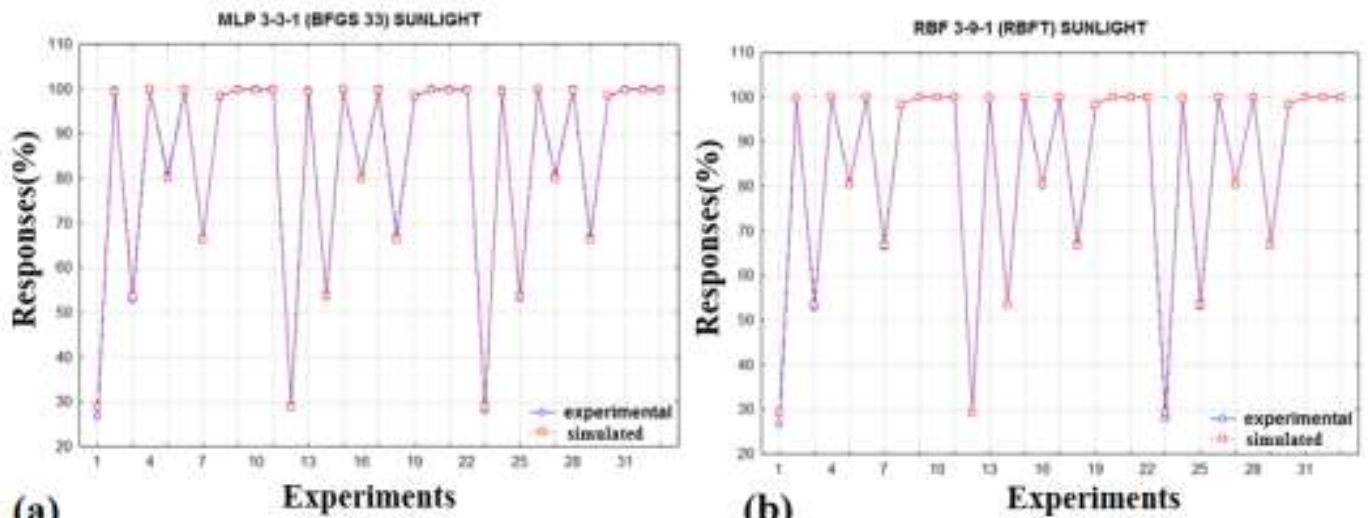

(a)

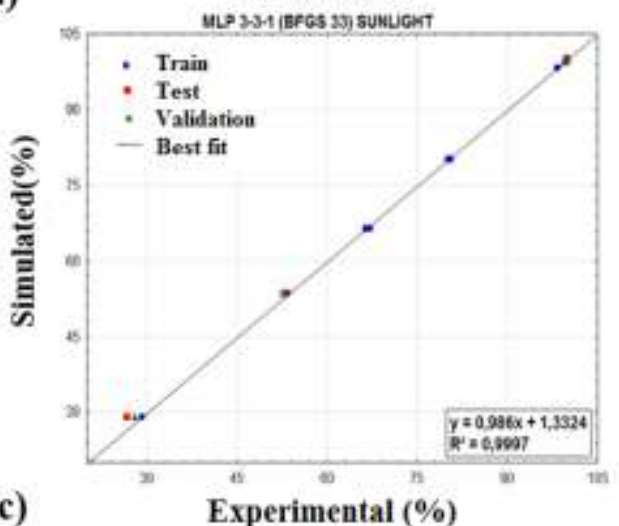

(b)

Experiments

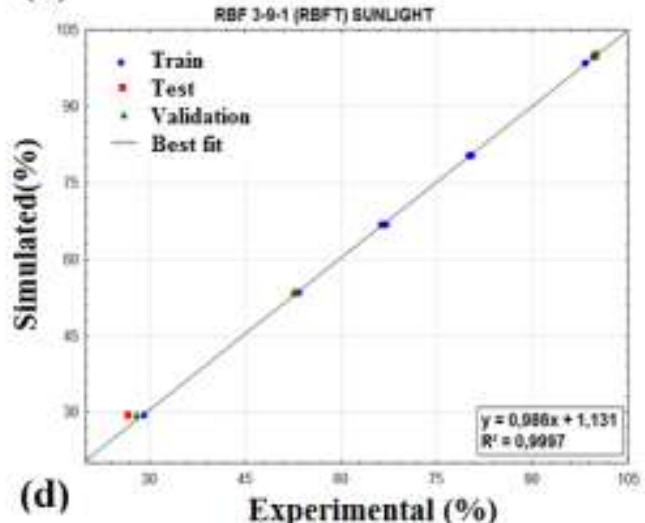

Figure 9: Comparison between the experimental and simulated values: a) MLP; b) RBF.Linear regression between the experimental and simulated results: c) MLP; d) RBF. 

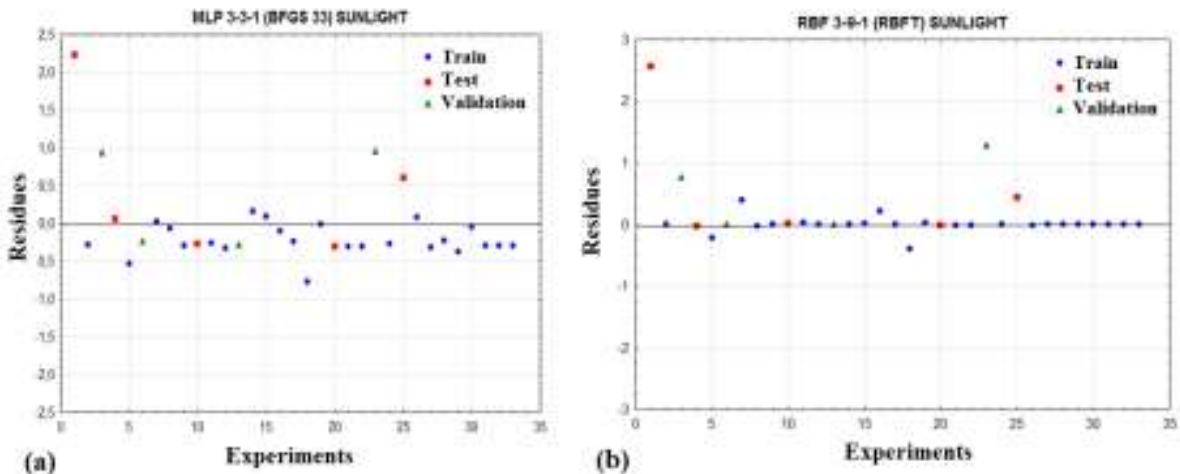

Figure 10: Residual plot of 4-chlorophenol degradation, regarding the difference between experimental and calculated values using ANN models.

\section{Conclusion}

The validation of the analytical method employed for detecting 4-Chlorophenol was therefore considered successful. All parameters of validation analysed complied with the norms established by the national regulatory bodies (ANVISA and INMETRO).

The degradation of 4-Chlorophenol using AOPs proved highly efficient on both systems, with the maximum results being showed at the centre point of the factorial design, for concentrations of $\mathrm{Fe}^{2+}=5 \mathrm{mg} \cdot \mathrm{L}^{-1}$, volume of $\mathrm{H}_{2} \mathrm{O}_{2}=0.75 \mathrm{~mL}$ and time $=90$ minutes. Through the analysis of the Pareto Charts and Surface Graphs, it is observed that the factors that most influence the degradation of the compound are the concentration of iron (II) ions and reaction time.

Furthermore, using ANN modelling of the degradation systems resulted in precise data. The coefficients of linear regression for both systems (UV-C and Sunlight-driven), for both MLP and RBF ANNs, were greater than 0.99. It is possible to verify, using the linear regression graphs between the values found and the values calculated (Figures 6(a) and 6(b)) and the residual plots (Figures 7(a) and 7(b)), that the values correlate satisfactorily. Still regarding the residual plots, it is possible to conclude that no dispersion pattern of the values is shown, being an additional indicator that the model chosen is appropriate.

\section{Acknowledgment}

The authors would like to express their upmost gratitude to FACEPE/NUQAAPE, CAPES, CNPq/INCTAA for financial support.

\section{References}

[1]. HE, S.; SUN, W.; WANG, J.; CHEN, L.;ZHANG, Y.; YU, J. Enhancement of biodegradability of real textile and dyeing wastewater by electron be am irradiation. Radiation Physics and Chemistry, v.124, p. 203-207, 2015

[2]. GARBA, Z. N.; RAHIM, A. A. Evaluation of optimal activated carbon from anagricultural waste for the removal ofparachlorophenol and 2,4-dichlorophenol. Process Safety and Environmental Protection, v.102, p.54-63, 2016.

[3]. SUN, Y.; CHEN, Z.; WU, G.; WU, Q.; ZHANG, F.; NIU, Z.; HU, H. Characteristics of water quality of municipal wastewater treatment plants in China: implications for resources utilization and management. Journal of Cleaner Production, v. 131, p. 1-9, 2016.

[4]. CUNHA, F. S.; AGUIAR, A. P. Métodos para a remoção de derivados fenólicos de efluentes aquosos. Revista Virtual Química, p. 844-865, 2014

[5]. PENG, Y.; CHEN, J.; LU, S.; HUANG, J.; ZHANG, M.; BUEKENS, A.; LI, X.; YAN, J. Chlorophenols in Municipal Solid Waste Incineration: A review.Chemical Engineering Journal, v. 292, p. 398-414, 2016.

[6]. CHEN, M.; XUA, P.; ZENG, G.; YANG, C.; HUANG, D.; ZHANG, J. Bioremediation of soils contaminated with polycyclic aromatic hydrocarbons, petroleum, pesticides, chlorophenols and heavymetals by composting: Applications, microbes and future research needs. Biotechnology Advances, v.33, p 745-755, 2015.

[7]. DING, H.; LI, X.; WANG, J.; ZHANG, X; CHEN, C. Adsorption of chlorophenols from aqueous solutions by pristine and surface functionalized single-walled carbon nanotubes. Journal of Environmental Sciences, v. 528, 2015.

[8]. NOURMORADI, H.; AVAZPOURA, M.; GHASEMIANB, N.; HEIDARIC, M.; MORADNEJADID, K.; KHODARAHMIA, F.; JAVAHERIA, M.; MOHAMMADI MOGHADAM, F. Surfactant modified montmorillonite as a low cost adsorbent for 4chlorophenol: Equilibrium, kinetic and thermodynamic study. Journal of the Taiwan Institute of Chemical Engineers, p. 244$251,2015$.

[9]. PENGHUI DU, P.; ZHAO, H.; LI, H.; ZHANGA, D.; HUANG, C.; DENG, M.; CHENMINGLIU, C.; CAO, H. Transformation, products, and pathways of chlorophenols via electro-enzymatic catalysis: How to control toxic intermediate products.Chemosphere, v. 144, p. 1674-1681, 2016.

[10]. VALLEJO, M.; FERNANDEZ-CASTRO, P.; ROMAN, M. F. S.; ORTIZ, I. Assessment of PCDD/Fs formation in the Fenton oxidation of 2-chlorophenol: Influence of the iron dose applied.Chemosphere, v. 137, p 135-141, 2015. 
[11]. ZHONG, B, W.; WANG, D.; XU, X. Phenol removal efficiencies of sewage treatment processes and ecological risks associated with phenols in effluents. JournalofHazardousMaterials, v. 217-218, p. 286-292, 2012.

[12]. BRANDÃO, Y. B.; TEODOSIO, J.; DIAS, F.; EUSTÁQUIO, W.; BENACHOUR, M. Treatment of phenolic effluents by a thermochemical oxidation process (DiCTT) and modelling by artificial neural networks. Fuel, v. 110, p. 185-195, 2013.

[13]. RIBANI, M.; BOTTOLI, C. B. G.; COLLINS, C. H.; JARDIM, I. C. S. F.; MELO, L. F. C. Validação em métodos cromatográficos e eletroforéticos. Química Nova, v. 27, n. 5, p. 771-780, 2004

[14]. LANCCAS, F. M. A Cromatografia Líquida Moderna e a Espectrometria de Massas: finalmente "compatíveis"? Scientia chromatographica, v.1, p.35-61, 2004.

[15]. INSTITUTO NACIONAL DE METROLOGIA, NORMALIZAÇÃO E QUALIDADE INDUSTRIAL (INMETRO), Orientações sobre Validação de Métodos de Ensaios Químicos - Revisão: 01 de março de 2003, Brasil.

[16]. ANVISA, Disponível em <www.anvisa.gov.br/medicamentos/conceito>, Acesso em: 12 Out. 2016.

[17]. PERLATTI, B.; SILVA, M. F. G. F.; FERNANDES, J. B.; FORIM, M. R. Validationandapplicationof HPLC-ESI-MS/MS method for thequantificationof RBBR decolorization, a model for highlytoxicmolecules, usingseveralfungistrains. Bioresource Technology, v.124, p.37-44, 2012.

[18]. LANAGRO - REDE DE LABORATÓRIOS NACIONAIS AGROPECUÁRIOS. Manual de validação, verificação/confirmação de desempenho, estimativa da incerteza de medição e controle de qualidade intralaboratorial, Divisão de Ensaios Químicos Coordenação-Geral de Apoio Laboratorial, DEQ/CGAL, 2014.

[19]. KHATAMIAN, M.; DIVBAND, B.; JODAEI, A. Degradation of 4-nitrophenol (4-NP) using ZnO nanoparticles supported on zeolites and modeling of experimental results by artificial neural networks. Materials Chemistry and Physics 134 (2012) 31-37.

[20]. RASOULIFARD, M. H.; SEYED DORRAJI, M. S.; AMANI-GHADIM, A. R.; KESHAVARZ-BABAEINEZHAD, N. Visiblelight photocatalytic activity of chitosan/polyaniline/CdS nanocomposite: Kinetic studies and artificial neural network modeling. Applied Catalysis A: General 514 (2016) 60-70.

Table 1: Variables in the factorial design.

\begin{tabular}{|c|c|c|c|}
\hline Experiment & $\mathbf{F e}^{\mathbf{2 +}}\left(\mathbf{m g .} \mathbf{L}^{\mathbf{- 1}}\right)$ & $\left.\mathbf{H}_{\mathbf{2}} \mathbf{O}_{\mathbf{2}} \mathbf{( m L}\right)$ & Time (minutes) \\
\hline 1 & 0 & 0.50 & 60 \\
\hline 2 & 10 & 0.50 & 60 \\
\hline 3 & 0 & 1.00 & 60 \\
\hline 4 & 10 & 1.00 & 60 \\
\hline 5 & 0 & 0.50 & 120 \\
\hline 6 & 10 & 0.50 & 120 \\
\hline 7 & 0 & 1.00 & 120 \\
\hline 8 & 10 & 1.00 & 120 \\
\hline 9 & 5 & 0.75 & 90 \\
\hline 10 & 5 & 0.75 & 90 \\
\hline 11 & 5 & 0.75 & 90 \\
\hline
\end{tabular}

Table 2: Values of the areas obtained for all the tests

\begin{tabular}{|c|c|c|c|c|c|c|c|c|}
\hline $\begin{array}{c}\mathbf{C}_{\mathbf{6}} \mathbf{H}_{\mathbf{5}} \mathbf{O C l} \\
(\mathbf{m g} / \mathbf{L})\end{array}$ & Area 1 & Area 2 & Area 3 & Area 4 & Area 5 & Area 6 & Area 7 & Average \\
\hline 10 & 278575.00 & 300642.50 & 277028.50 & 317968.00 & 312081.50 & 308915.70 & 294508.30 & 298531.40 \\
\hline 20 & 682291.70 & 643368.00 & 674422.30 & 660537.30 & 626914.50 & 647561.00 & 611097.00 & 649456.00 \\
\hline 30 & 969359.300 & 944770.30 & 926459.30 & 944730.30 & 971643.30 & 1007823.00 & 998687.30 & 966210.40 \\
\hline 40 & 1206225.00 & 1209217.00 & 1203571.00 & 1167374.00 & 1165693.00 & 1203352.00 & 1140369.00 & 1185114.00 \\
\hline 50 & 1607737.00 & 1529624.00 & 1524280.00 & 1512768.00 & 1454972.00 & 1491320.00 & 1411936.00 & 1504663.00 \\
\hline 60 & 1900178.00 & 1817081.00 & 1794235.00 & 1729440.00 & 1850076.00 & 1825583.00 & 1709713.00 & 1803758.00 \\
\hline 70 & 2207865.00 & 2083483.00 & 2157488.00 & 2038341.00 & 2034784.00 & 1994631.00 & 2000974.00 & 2073938.00 \\
\hline 80 & 2697971.00 & 2547397.00 & 2461272.00 & 2536981.00 & 2618367.00 & 2633148.00 & 2727522.00 & 2603237.00 \\
\hline
\end{tabular}

Table 3: Precision analysis

\begin{tabular}{|c|c|c|c|c|c|}
\hline \multirow{2}{*}{$\begin{array}{c}\mathbf{C}_{6} \mathbf{H}_{\mathbf{5}} \mathbf{O C C} \\
\left(\mathbf{m g .} \mathbf{L}^{-\mathbf{1}}\right)\end{array}$} & Average & \multirow{2}{*}{$\begin{array}{c}\text { Standard } \\
\text { deviation }\end{array}$} & \multicolumn{2}{|c|}{$\begin{array}{c}\text { Grubb's Test 95\% } \\
\text { confidence }\end{array}$} & \multirow{2}{*}{$\begin{array}{c}\text { Coefficient of } \\
\text { variance }\end{array}$} \\
\cline { 4 - 5 } & & & $\mathbf{G}<$ & $\mathbf{G}>$ & \\
\hline 10 & 298531.40 & 16075.31 & 1.241 & 1.209 & 5.38 \\
\hline 20 & 649456.00 & 25312.98 & 1.515 & 1.297 & 3.90 \\
\hline 30 & 966210.40 & 29796.56 & 1.334 & 1.396 & 3.08 \\
\hline 40 & 1185114.00 & 27061.26 & 1.653 & 0.891 & 2.28 \\
\hline 50 & 1504663.00 & 61837.75 & 1.500 & 1.667 & 4.11 \\
\hline 60 & 1803758.00 & 66526.21 & 1.414 & 1.449 & 3.69 \\
\hline 70 & 2073938.00 & 81057.27 & 0.978 & 1.652 & 3.91 \\
\hline 80 & 2603237.00 & 94169.15 & 1.508 & 1.320 & 3.62 \\
\hline
\end{tabular}

Table 4: Accuracy analysis

\begin{tabular}{|c|c|c|}
\hline Concentration $(\mathbf{m g} / \mathbf{L})$ & Average area & Recovery percentage $(\%)$ \\
\hline $10+20$ & 886853.30 & 62.90 \\
\hline $10+40$ & 1471331.00 & 83.00 \\
\hline $10+60$ & 2167915.00 & 72.70 \\
\hline
\end{tabular}


Table 4: Accuracy analysis

\begin{tabular}{|c|c|c|}
\hline Concentration $(\mathbf{m g} / \mathbf{L})$ & Average area & Recovery percentage (\%) \\
\hline $10+20$ & 886853.30 & 62.90 \\
\hline $10+40$ & 1471331.00 & 83.00 \\
\hline $10+60$ & 2167915.00 & 72.70 \\
\hline
\end{tabular}

Table 5: Analysis of variance of the degradation model of 4-Chlorophenol for the UV-C system.

\begin{tabular}{|c|c|c|c|}
\hline \multirow{2}{*}{ Degradation of 4-Chlorophenol } & Fonte da variação & Quadratic sum & Degrees of freedom \\
\cline { 2 - 4 } & Regression & 149.2613 & 7 \\
\cline { 2 - 4 } & Residues & 44.3375 & 3 \\
\cline { 2 - 4 } & Lack of fit & 44.3374 & 1 \\
\cline { 2 - 4 } & Pure error & 0.0001 & 2 \\
\cline { 2 - 4 } & Total & 193.5988 & 10 \\
\hline \% variation explained & 77.09 & \\
\cline { 2 - 4 } \% Maximum explained variation & 99.99 & \\
\hline
\end{tabular}

Table 6: Analysis of variance of the 4-Chlorophenol degradation model for the Sunlight system.

\begin{tabular}{|c|c|c|c|}
\hline & Variation Source & Quadratic sum & Degrees of freedom \\
\hline \multirow{3}{*}{$\begin{array}{c}\text { Degradation of 4- } \\
\text { Chlorophenol }\end{array}$} & Regression & 5261.967 & 7 \\
\cline { 2 - 4 } & Residues & 1049.849 & 3 \\
\cline { 2 - 4 } & Lack of fit & 1049.849 & 2 \\
\cline { 2 - 4 } & Pure error & 0.000 & 10 \\
\cline { 2 - 4 } & Total & 6311.816 & \\
\hline \multirow{2}{*}{$\begin{array}{c}\text { \% variation explained } \\
\text { \% Maximum explaned variation }\end{array}$} & 83.37 & 100.00 & \\
\cline { 2 - 4 }
\end{tabular}

Table 7: Characteristics of the resulting RNAs for the UV-C system.

\begin{tabular}{|c|c|c|c|c|c|c|c|}
\hline Model & Train & Test & Validation & Training & Error & \multicolumn{2}{|c|}{ Activation function } \\
\cline { 5 - 7 } & $\left(\mathbf{R}^{\mathbf{2}}\right)$ & function & Hidden layer & Output \\
\hline MLP 3-4-1 & 0,9915 & 1,0000 & 0,9998 & BFGS 42 & SOS & Tanh & Identity \\
\hline RBF 3-10-1 & 0,9912 & 1,0000 & 0,9998 & RBFT & SOS & Gaussian & Identity \\
\hline
\end{tabular}

Table 8: Characteristics of the resulting RNAs for the Sunlight system

\begin{tabular}{|c|c|c|c|c|c|c|c|}
\hline \multirow[t]{2}{*}{ Model } & \multirow{2}{*}{$\begin{array}{c}\text { Train } \\
\left(\mathbf{R}^{2}\right)\end{array}$} & \multirow{2}{*}{$\begin{array}{l}\text { Test } \\
\left(\mathbf{R}^{2}\right)\end{array}$} & \multirow{2}{*}{$\begin{array}{c}\text { Validation } \\
\left(\mathbf{R}^{2}\right)\end{array}$} & \multirow{2}{*}{$\begin{array}{c}\text { Training } \\
\text { Algorithm }\end{array}$} & \multirow{2}{*}{$\begin{array}{l}\text { Error } \\
\text { function }\end{array}$} & \multicolumn{2}{|c|}{ Activation function } \\
\hline & & & & & & Hidden layer & Output \\
\hline MLP 3-3-1 & 0.9999 & 0.9999 & 1.0000 & BFGS 33 & SOS & Tanh & Sine \\
\hline RBF 3-9-1 & 1.0000 & 0.9999 & 1.0000 & RBFT & SOS & Gaussian & Identity \\
\hline
\end{tabular}

Table 9: Values of weights in the entry, concealment and exit layers for the MLP RNA of the UV-C system.

\begin{tabular}{|c|c|c|c|c|c|}
\hline \multirow{2}{*}{ Neuron } & \multicolumn{5}{|c|}{ Weights } \\
\cline { 2 - 6 } & $\mathbf{F e}^{\mathbf{2 +}}$ & $\mathbf{H}_{\mathbf{2}} \mathbf{O}_{\mathbf{2}}$ & Time & Bias input layer & Degradation of 4-Chlorophenol \\
\hline 1 & 0.67427 & -0.50804 & -3.36416 & -0.03893 & 0.36916 \\
\hline 2 & 0.53648 & -1.17818 & -0.83362 & 0.44547 & 1.12061 \\
\hline 3 & 0.82960 & -3.04096 & 0.51670 & 2.70919 & -0.86489 \\
\hline 4 & -0.79736 & -2.87777 & -0.80318 & 0.01855 & -0.46895 \\
\hline- & - & - & - & Bias hidden layer & 0.39943 \\
\hline
\end{tabular}

Table 10: Values of weights in the incoming, hidden and output layers for the MLP RNA of the Sunlight system.

\begin{tabular}{|c|c|c|c|c|c|}
\hline \multirow{2}{*}{ Neuron } & \multicolumn{5}{|c|}{ Weights } \\
\cline { 2 - 6 } & $\mathbf{F e}^{\mathbf{2 +}}$ & $\mathbf{H}_{\mathbf{2}} \mathbf{O}_{\mathbf{2}}$ & Time & Bias input layer & Degradation of 4-Chlorophenol \\
\hline 1 & 0.09064 & 3.81772 & -1.52163 & 0.70499 & 0.36095 \\
\hline 2 & -0.44794 & -0.87311 & 0.84870 & -1.12635 & 0.83482 \\
\hline 3 & 0.09517 & 1.42596 & -0.34088 & -0.26968 & 0.77159 \\
\hline- & & & & Bias hidden layer & 0.65525 \\
\hline
\end{tabular}

Table 11: Values of weights in the entry. concealment and exit layers for the RBF RNA of the UV-C system.

\begin{tabular}{|c|c|c|c|c|c|}
\hline \multirow{2}{*}{ Neuron } & \multicolumn{5}{|c|}{ Weights } \\
\cline { 2 - 6 } & $\mathbf{F e}^{2+}$ & $\mathbf{H}_{\mathbf{2}} \mathbf{O}_{\mathbf{2}}$ & Time & Bias input layer & Degradation of 4-Chlorophenol \\
\hline 1 & 1.0000 & 0.0000 & 0.0000 & 0.8660 & 0.0222 \\
\hline 2 & 1.0000 & 0.0000 & 0.0000 & 0.8660 & 2.8013 \\
\hline 3 & 1.0000 & 0.5000 & 0.0000 & 0.8660 & 2.5271 \\
\hline
\end{tabular}


Degradation Of 4-Chlorophenol Using Advanced Oxidative Processes And Artificial Neural ..

\begin{tabular}{|c|c|c|c|c|c|}
\hline 4 & 0.5000 & 0.5000 & 0.0000 & 0.8660 & 2.8270 \\
\hline 5 & 0.5000 & 0.5000 & 1.0000 & 0.8660 & 2.5809 \\
\hline 6 & 0.5000 & 1.0000 & 0.0000 & 0.8660 & 0.0335 \\
\hline 7 & 0.5000 & 1.0000 & 0.0000 & 0.8660 & 2.1279 \\
\hline 8 & 0.5000 & 1.0000 & 0.0000 & 0.8660 & -13.6560 \\
\hline 9 & 0.5000 & 1.0000 & 0.0000 & 0.8660 & 2.9007 \\
\hline 10 & 1.0000 & 1.0000 & 1.0000 & 0.8660 & 5.7683 \\
\hline- & - & - & - & Bias hidden layer & 0.2254 \\
\hline
\end{tabular}

Table 12: Values of the weights in the incoming. hidden. and output layers for the Sunlight RBF RNA.

\begin{tabular}{|c|c|c|c|c|c|}
\hline \multirow{2}{*}{ Neuron } & \multicolumn{5}{|c|}{ Weights } \\
\cline { 2 - 6 } & $\mathbf{F e}^{\mathbf{2 +}}$ & $\mathbf{H}_{\mathbf{2}} \mathbf{O}_{\mathbf{2}}$ & Time & Bias input layer & Degradation of 4-Chlorophenol \\
\hline 1 & 1.0000 & 1.0000 & 0.5000 & 0.8660 & -0.3931 \\
\hline 2 & 1.0000 & 1.0000 & 0.5000 & 0.8660 & -16.7629 \\
\hline 3 & 0.0000 & 1.0000 & 0.5000 & 0.8660 & 1.1365 \\
\hline 4 & 0.0000 & 0.0000 & 0.0000 & 0.8660 & 1.1595 \\
\hline 5 & 0.0000 & 1.0000 & 0.0000 & 0.8660 & -6.5735 \\
\hline 6 & 0.0000 & 1.0000 & 1.0000 & 0.8660 & 7.7857 \\
\hline 7 & 1.0000 & 1.0000 & 1.0000 & 0.8660 & 12.5509 \\
\hline 8 & 1.0000 & 0.0000 & 0.0000 & 0.8660 & 7.1653 \\
\hline 9 & 1.0000 & 0.0000 & 1.0000 & 0.8660 & -4.0552 \\
\hline- & - & - & - & Bias hidden layer & 0.3978 \\
\hline
\end{tabular}

